\title{
Generic protease detection technology for monitoring periodontal disease
}

\author{
Xinwei Zheng, ${ }^{a}$ Joseph P. Cook, ${ }^{a}$ Michael Watkinson, ${ }^{b}$ \\ Shoufeng Yang, ${ }^{a}$ Ian Douglas, ${ }^{c}$ Andrew Rawlinson ${ }^{c}$ \\ and Steffi Krause $* a$
}

\author{
Received 18th May 2010, Accepted 21st July 2010 \\ DOI: 10.1039/c005364c
}

\begin{abstract}
Periodontal diseases are inflammatory conditions that affect the supporting tissues of teeth and can lead to destruction of the bone support and ultimately tooth loss if untreated. Progression of periodontitis is usually site specific but not uniform, and currently there are no accurate clinical methods for distinguishing sites where there is active disease progression from sites that are quiescent.

Consequently, unnecessary and costly treatment of periodontal sites that are not progressing may occur. Three proteases have been identified as suitable markers for distinguishing sites with active disease progression and quiescent sites: human neutrophil elastase, cathepsin G and MMP8. Generic sensor materials for the detection of these three proteases have been developed based on thin dextran hydrogel films cross-linked with peptides. Degradation of the hydrogel films was monitored using impedance measurements. The target proteases were detected in the clinically relevant range within a time frame of $3 \mathrm{~min}$. Good specificity for different proteases was achieved by choosing appropriate peptide cross-linkers.
\end{abstract}

\section{Introduction}

Periodontal diseases are a group of related inflammatory conditions affecting the supporting tissues of teeth. Inflammation of the gums (gingivae) is caused by the local accumulation of an oral biofilm, dental plaque. In its most severe form the disease can lead to destruction of the tooth supporting tissues, including resorption of alveolar bone and loss of teeth. There are several distinct clinical forms of periodontitis but chronic periodontitis, most frequently found in adults, is the most common. Disease progression is usually site specific but is not uniform and it is difficult to distinguish clinically those sites that are progressing from those that are inflamed but not progressing. As a result a considerable level of unnecessary treatment may occur of periodontal sites that are not progressing with consequent drain on resources. A non-invasive technique for more accurately identifying periods of acute inflammatory destruction would be of major benefit, which could be fulfilled by an accurate biosensor.

Both early in the pathogenesis of periodontitis and as acute exacerbations during its chronic course, neutrophils (PMNL) migrate to the site $^{1}$ and there is a fluid exudate (gingival crevicular fluid (GCF)) into the "pocket" between the tooth and the gingival tissue. Analysis of this fluid provides a convenient, non-invasive means

\footnotetext{
${ }^{a}$ School of Engineering and Materials Science, Queen Mary University of London, London, E1 4NS, UK. E-mail: s.krause@qmul.ac.uk; Fax: +44 20 89819804; Tel: +44 2078823747

${ }^{b}$ School of Biological and Chemical Sciences, Queen Mary University of London, London, E1 $4 N S, U K$

${ }^{c}$ School of Clinical Dentistry, Claremont Crescent, Sheffield, S10 2TA, UK
} 
of monitoring host or bacterial molecules. The PMNLs arriving in the periodontal pocket attempt to control the plaque biofilm by degranulation and release of lytic enzymes, which include the serine proteases (elastase, cathepsin G, proteinases-3), and the matrix metalloproteinases, MMP8 (collagenase) and MMP9 (gelatinaseB). Elastase activity has been detected in the GCF and is considered to be a useful quantitative measure of gingival inflammation. ${ }^{2}$ In addition, cathepsin $G$ and MMP8 have been correlated with disease severity ${ }^{3}$ but our work has shown that although MMP9 is present in an activated form in $40 \%$ of sites, it did not correlate with the clinical status of the sites. In contrast, elastase levels correlate with the degree of loss of attachment between tooth and supporting tissue and its levels mirror that of the neutrophil MMP8 in GCF. ${ }^{4}$ These also correlate with gingival and bleeding indices. ${ }^{5}$ In addition, elastase has been shown to damage epithelial cells directly. ${ }^{6}$ The major factor regulating elastase activity in the oral cavity and upper respiratory tract is thought to be secretory leukoproteinase inhibitor (SLPI) ${ }^{7}$ but this, like $\alpha 1$-antitrypsin, can be inactivated in the presence of free radicals such as those produced by the neutrophils.

From the proteases mentioned above, we have identified human neutrophil elastase (HNE), cathepsin G, and MMP8 as suitable markers for disease progression and therefore as target proteases for our detection technology. Some 0.05 to $\sim 30 \mathrm{U} \mathrm{ml}^{-1}$ of $\mathrm{HNE}$, and up to $2.4 \mathrm{mU} \mathrm{ml}^{-1}$ cathepsin- $\mathrm{G}$ have been measured in GFC. ${ }^{8}$ Activities of up to $0.7 \mathrm{mU} \mathrm{ml}^{-1}$ have been measured for MMP8. ${ }^{9}$ A point of care system for the diagnosis of periodontitis should be able to provide a result within a few minutes, while the patient is in the dental chair. Consequently, the work presented in this paper is directed at the development of a disposable biosensor for the above mentioned target proteases that would provide accurate chair side evaluation of protease levels, which in turn would immediately inform treatment decisions.

\section{Protease sensors based on the degradation of thin films}

Disposable sensors based on the degradation of thin films have shown great promise for the detection of proteases. ${ }^{10-18}$ In some cases, natural substrates of the target proteases were coated onto a variety of different transducers. For example, Saum et al. monitored collagenase activity by depositing its natural substrate gelatin onto interdigitated electrodes. ${ }^{19}$ Collagenase concentrations as low as $0.2 \mathrm{mg} \mathrm{ml}^{-1}$ were detected; however, only low electrolyte concentrations could be used for reliable impedance measurements due to the hydrophilic nature of the films. Millington et al. detected trypsin using holograms based on gelatin. ${ }^{10}$ Hanumegowda et al. employed an optical microsphere resonator coated with BSA to detect trypsin. ${ }^{12}$ Ionescu et al. introduced an amperometric sensor coated with gelatine for the detection of trypsin. ${ }^{13}$ Other natural protease substrates used in this sensor format included fibrinogen used for the detection of human neutrophil elastase by quartz crystal microbalance (QCM) and BSA cross-linked acrylamide degraded by pepsin. ${ }^{18}$

All of the protease sensors mentioned above are based on the measurement of the disappearance of the film from the transducer surface. Other sensors based on the enzymatic degradation of protein films have detected the formation of amino acids by optical means. ${ }^{15,20}$

A drawback of using natural enzyme substrates in the detection of proteases is a lack of specificity. Proteins contain a large number of different cleavage sites and are therefore likely to be degraded by a number of different proteases. Furthermore, the use of proteins makes the fine tuning of film properties for maximising the sensor response and reducing undesirable effects, such as non-specific binding, very difficult.

Greater specificity can be achieved using synthetic protease substrates. ${ }^{16,17}$ For example poly(ester amide) films based on bis(L-phenylalanine)- $\alpha, \omega$-alkylene diesters 
with a single cleavage site were used for the detection of $\alpha$-chymotrypsin. Film degradation was monitored using surface plasmon resonance, ${ }^{16,17}$ quartz crystal microbalance $^{21}$ and impedance measurements. ${ }^{21,22}$ The rate of degradation was found to be dependent on the enzyme concentration. The hydrophobic nature of the film caused a severe reduction in the sensor signal in the presence of BSA. ${ }^{16}$

A more generic approach has recently been described by Stair et al. ${ }^{14}$ Hydrogel films were formed by cross-linking oxidised dextran with two different peptides: AAPVAAK, preferentially cleaved by HNE, and AAPFFK, preferentially cleaved by cathepsin G. Degradation of the hydrogel films was monitored using a quartz crystal microbalance. Both hydrogel films showed good sensitivity towards their respective proteases, with little cross-sensitivity for the other enzyme. Moreover, the approach is generic as specificity for different proteases was achieved by choosing an appropriate peptide sequence as cross-linker. In addition, hydrogels are less likely to suffer from the effects of non-specific binding. ${ }^{16}$ A drawback of the use of peptide cross-linked dextran hydrogel films was that the degradation of the films in the presence of its target protease was preceded by a long induction period ranging from $1.5 \mathrm{~min}$ to $15 \mathrm{~min}$ depending on the protease activity rendering these films unsuitable for a fast chair side diagnostic.

In this study, a new coating method for peptide cross-linked dextran hydrogels has been explored to increase their response rate to the target proteases. Film degradation has been monitored using impedance measurements as this allows the use of cheap, disposable sensor substrates in any ultimate point of care device.

\section{Experimental}

\section{Materials}

Polished, gold-coated QCM crystals $(10 \mathrm{MHz})$ were purchased from ICM (Oklahoma City, USA). Silicon with $20 \mathrm{~nm}$ thermal oxide and $30 \mathrm{~nm}$ CVD nitride was purchased from Si-Mat (Landsberg, Germany). $96 \%$ alumina ( $0.5 \mathrm{~mm}$ thick) was purchased from Laser cutting-ceramic Ltd. (Sheffield, UK).

Dextran $\left(M_{\mathrm{r}}=2 \times 10^{6} \mathrm{Da}\right)$ was purchased from Fluka. Peptide sequences AAPVAAK, AAPFFK, GPQGIWGQK (95\% purity) were purchased from Genscript (New Jersey, USA). Each peptide sequence was dissolved in water to a concentration of $100 \mathrm{mg} \mathrm{m}^{-1}$ and filtered through a PL-HCO3 MP solid phase extraction (SPE) tube purchased from Polymer Laboratories (Massachusetts, USA) to neutralise the TFA salts and freeze dried before use. Human neutrophil elastase (HNE) and cathepsin G were purchased from Elastin Products (Missouri, USA). Matrix metalloproteinase 8 (MMP 8) was purchased from Calbiochem (Darmstadt, Germany).

Photoresist S1813 and developer 351 were purchased from Chestech Ltd (Rugby, UK). Other chemicals and reagents were obtained from commercial sources (SigmaAldrich, Fisher Scientific) and used without further purification. Ultra pure water was obtained from an ELGA Purelab Ultra system.

The following buffer solutions were prepared:

- $\mathrm{pH} 8.0$ phosphate buffer $(10 \mathrm{mM})$;

- pH 7.5 charge transfer buffer: pH 7.5 phosphate buffered saline $(10 \mathrm{mM})$ containing $5 \mathrm{mM}$ potassium ferricyanide, $5 \mathrm{mM}$ of potassium ferrocyanide and $140 \mathrm{mM}$ sodium chloride;

- $\mathrm{pH} 5$ charge transfer buffer: $\mathrm{pH} 5$ sodium acetate buffer $(1 \mathrm{mM})$ containing $5 \mathrm{mM}$ potassium ferricyanide, $5 \mathrm{mM}$ of potassium ferrocyanide and $140 \mathrm{mM}$ sodium chloride.

\section{Fabrication of electrodes}

Chromium/gold interdigitated electrodes were patterned onto silicon substrates with a $\mathrm{SiO}_{2} / \mathrm{Si}_{3} \mathrm{~N}_{4}$ insulator and $96 \%$ alumina substrates. $\mathrm{S} 1813$ photoresist was spincoated using CHEMAT Technology spin coater kw-4A and exposed with a Karl 
Suss MicroTec MJB3 mask aligner following a standard procedure. The exposed photoresist was left in chlorobenzene for $10 \mathrm{~min}$ to harden the film surface. The photoresist was then developed. Some $30 \mathrm{~nm}$ chromium and $150 \mathrm{~nm}$ gold were deposited by thermal evaporation using an Edwards Coating System E306A, followed by lift-off in acetone. Interdigitated electrodes with $10 \mu \mathrm{m}$ line width and $10 \mu \mathrm{m}$ line spacing were patterned on the silicon substrates. Interdigitated electrodes with $50 \mu \mathrm{m}$ line width and $300 \mu \mathrm{m}$ spacing were patterned on the alumina substrate.

\section{Oxidation of dextran}

Dextran was oxidised adapting a procedure described by Ruys et $a l^{23}$ Sodium periodate $(1.41 \mathrm{~g}, 6.6 \mathrm{mmol})$ was added cautiously to a stirred dextran $(0.48 \mathrm{~g}, 3 \mathrm{mmol}$ repeat units) solution in $7 \mathrm{ml}$ de-ionized water. The mixture was left for $24 \mathrm{~h}$ in the dark. The oxidized dextran solution was then dialyzed against 11 water using Spectra/Por Float-a-Lyser (MWCO 500) from Spectrum Laboratories Inc for 2 days. (California, USA). The bulk water was changed three times during dialysis. After freeze drying, a white fluffy solid was obtained $(0.32 \mathrm{~g}, 83 \%)$, which was stored at room temperature. The degree of oxidation of dextran was confirmed to be $100 \%$ by titration as described previously, ${ }^{14}$ i.e. each glucose unit was modified with two aldehyde groups resulting in a decrease of molecular weight of the repeat units from $162 \mathrm{~g} \mathrm{~mol}^{-1}$ to $130 \mathrm{~g} \mathrm{~mol}^{-1}$ during oxidation. $\delta_{\mathrm{H}}\left(270 \mathrm{MHz}, \mathrm{D}_{2} \mathrm{O}, \mathrm{Me}_{4} \mathrm{Si}\right)$ $3.80\left(\mathrm{~b}, \mathrm{CH}_{2}\right) 4.02(\mathrm{~b}, \mathrm{CH}), 5.10(\mathrm{~b}, \mathrm{CH}), 5.39$ (b, $\left.\mathrm{CHOH}\right), 8.38$ (s, CHO). IR: $\left(\mathrm{cm}^{-1}\right) 3375(\mathrm{OH}), 2934(\mathrm{CH}), 1637(\mathrm{CHO}), 1342,1103,1021$.

\section{Film preparation}

Hydrogel films were prepared following two different procedures. For comparison with previous results, gold coated quartz crystals were coated by spin-coating a solution of oxidised dextran and peptide following the procedure described by Stair et al. ${ }^{14}$ To overcome the problems encountered with these films, a new coating procedure was developed where oxidised dextran and peptide were deposited successively.

The interdigitated electrodes/quartz crystals were immersed in piranha solution ( $3: 1 \mathrm{v} / \mathrm{v}$ concentrated $\mathrm{H}_{2} \mathrm{SO}_{4}$ and $30 \% \mathrm{H}_{2} \mathrm{O}_{2}$ ) for one minute. After rinsing with water, the electrodes were transferred into a $10 \mathrm{mM}$ solution of 4-mercapto-1butanol in $4: 1 \mathrm{v} / \mathrm{v}$ ethanol and water and left for one hour to form a self-assembled monolayer. Afterwards, the electrodes were rinsed with water and dried with nitrogen. A solution of oxidized dextran $(6.5 \mathrm{mg}, 0.05 \mathrm{mmol}$ repeat units $)$ in $\mathrm{pH}$ 8.0 phosphate buffer $(0.5 \mathrm{ml})$ was then spin-coated at $3000 \mathrm{rpm}$ for $25 \mathrm{~s}$ onto the surface of the electrode. The coated dextran layer was left in a sample box at room temperature overnight to dry. A solution of AAPVAAK (3.1 mg, $0.005 \mathrm{mmol})$ in $\mathrm{pH} 8.0$ phosphate buffer $(50 \mu \mathrm{l})$ was prepared. Some $200 \mu \mathrm{l}$ of methanol was then added and mixed with a vortex mixer. The solution of AAPVAAK was then drop coated onto the surface of the dextran layer. The amount of AAPVAAK solution for drop coating was dependent on the area of the electrode. Specifically, $0.5 \mu \mathrm{l}$ of AAPVAAK solution was drop coated onto a $3 \mathrm{~mm} \times 3 \mathrm{~mm}$ electrode area. Film curing was finished by incubating the film at $30^{\circ} \mathrm{C}$ for 1 day. The thickness of the film on the silicon substrate was measured to be $200-300 \mathrm{~nm}$ thick using a Dektak ${ }^{3}$ ST surface profiler. The thickness of the film on the alumina surface could not be measured due to the surface roughness of the substrate. The average grain size of alumina was estimated to be about $2 \mu \mathrm{m}$ using an SEM.

AAPVAAK cross-linked hydrogel films were used for the detection of HNE, AAPFFK cross-linked films were used for the detection of cathepsin G. These peptide sequences were previously used by Stair et al. ${ }^{14}$ MMP8 activated by $p$-aminophenylmercuric acetate using organomercurial activation protocol was detected using GPQGIWGQK as the cross-linker. This peptide sequence was obtained by adding lysine to a peptide that was shown to be a preferred substrate for MMP8 
previously ${ }^{24}$ to obtain an amine functionality at the $\mathrm{C}$ terminal of the peptide. Crosslinking with AAPFFK and GPQGIWGQK was carried out using the same molar concentration as described for AAPVAAK above. Initial investigations were carried out using the AAPVAAK cross-linked hydrogel because of the low cost of HNE compared to the other enzymes.

\section{Film degradation experiments}

The hydrogel coated interdigitated electrodes were inserted into a customized cell with an o-ring to insulate the contacts from the solution and a magnetic stirrer bar. Some $950 \mu$ of $\mathrm{pH} 7.5$ charge transfer buffer was then added to the cell at room temperature. The charge transfer buffer was constantly stirred and the impedance measured with time in a frequency range from $10 \mathrm{~Hz}$ to $50 \mathrm{kHz}$ using an Autolab PGSTAT10 with FRA2 (Windsor Scientific, UK). All impedance measurements were carried out between the two electrodes of the interdigitated structure with an ac voltage amplitude of $10 \mathrm{mV}$ and at a dc potential of $0 \mathrm{~V}$. The impedance usually became stable after $15 \mathrm{~min}$, and then $50 \mu \mathrm{l}$ of different concentration enzyme solution in $\mathrm{pH} 5$ charge transfer buffer was added into the $\mathrm{pH} 7.5$ charge transfer buffer in the cell. After the addition of enzyme, an impedance change was generally observed in less than $30 \mathrm{~s}$. A control experiment was carried out by replacing the enzyme solution with $\mathrm{pH} 5$ charge transfer buffer.

For measurements in the presence of $2 \%$ BSA, $250 \mu 1$ of $8 \%$ BSA solution in $\mathrm{pH} 7.5$ charge transfer buffer was added to $700 \mu$ l of $\mathrm{pH} 7.5$ charge transfer buffer followed by the addition of $50 \mu$ of enzyme solution in $\mathrm{pH} 5$ charge transfer buffer after the 15 min stabilisation period.

\section{Measurements in small sample volumes}

Capillary fill devices were constructed on top of the hydrogel coated IDEs on $96 \%$ alumina after coating the hydrogel as described above. A single-sided adhesive tape was attached to the hydrogel-coated electrode surface as an insulator that also formed a well around the electrode followed by a double-sided adhesive as a spacer and a hydrophilic lid manufactured by Adhesives Research Ireland Ltd. A schematic of the device is shown in Fig. 1. The volume of the capillary fill device was about $1.5 \mu \mathrm{l}$. After filling the device with test solution, it was sealed from both sides of the capillary channel using silicone grease to prevent evaporation of the

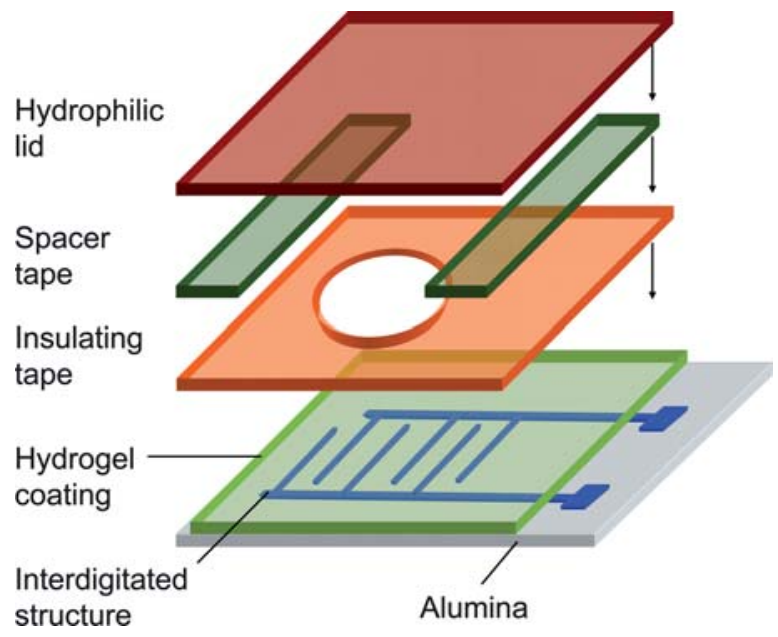

Fig. 1 Schematic of capillary fill device. 
solution. Impedance changes were monitored using an Autolab PGSTAT10 with FRA2 at $100 \mathrm{~Hz}$.

\section{Standard characterisation techniques}

${ }^{1} \mathrm{H}$ and ${ }^{13} \mathrm{C}$ NMR spectra were recorded on a Jeol Ex270 instrument at room temperature. Infrared spectra were recorded on a Bruker Tensor 37 FT-IR system with an ATR diamond press. Scanning electron microscope images were obtained from FEI Inspect $F$ instrument with acceleration voltages of $10 \mathrm{keV}$. Optical microscope image was obtained from OLYMPUS BX60 microscope.

\section{Results and discussion}

The impedance change during the enzyme induced degradation of the peptide crosslinked hydrogel films was initially investigated using gold-coated quartz crystals as substrates for the hydrogel to allow comparison with previous data obtained with quartz crystal microbalance measurements. ${ }^{14}$ Impedance spectra were measured in a two electrode arrangement using a platinum electrode as the counter electrode. No impedance change was observed during the degradation of an AAPVAAK cross-linked hydrogel film by HNE in phosphate buffered saline. This was attributed to the hydrophilicity of the film resulting in a significant uptake of electrolyte and therefore a low film resistance. In the presence of a charge transfer reagent (ferricyanide/ferrocyanide), a significant change in impedance was observed at the low frequency end of the spectrum (Fig. 2) due to the change in the charge transfer resistance during the degradation of the film. Hence subsequent degradation experiments were carried out at frequencies between $30 \mathrm{~Hz}$ and $100 \mathrm{~Hz}$.

\section{Two-step coating of hydrogel films}

Hydrogel films produced using a single step method where a solution containing both oxidised dextran and the peptide was spin-coated onto a quartz crystal showed a relatively slow response preceded by an induction period when measured by QCM measurements. ${ }^{14} \mathrm{~A}$ similar result was obtained when measuring the degradation of these hydrogel films by impedance measurements (Fig. 3, curve A). The impedance was stable in $\mathrm{pH} 7.5$ charge transfer buffer, it increased briefly upon addition of HNE and then decreased slowly over a long period of time.

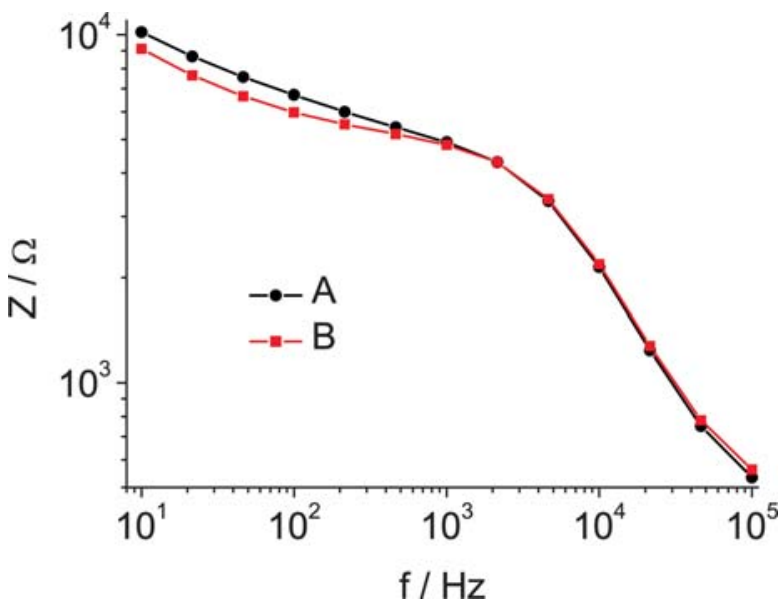

Fig. 2 Impedance spectra of AAPVAAK cross-linked hydrogel films prepared by a one-step coating method before (A) and after (B) the addition of $10 \mathrm{U} \mathrm{ml}^{-1} \mathrm{HNE}$ to $\mathrm{pH} 7.5$ charge transfer buffer. 


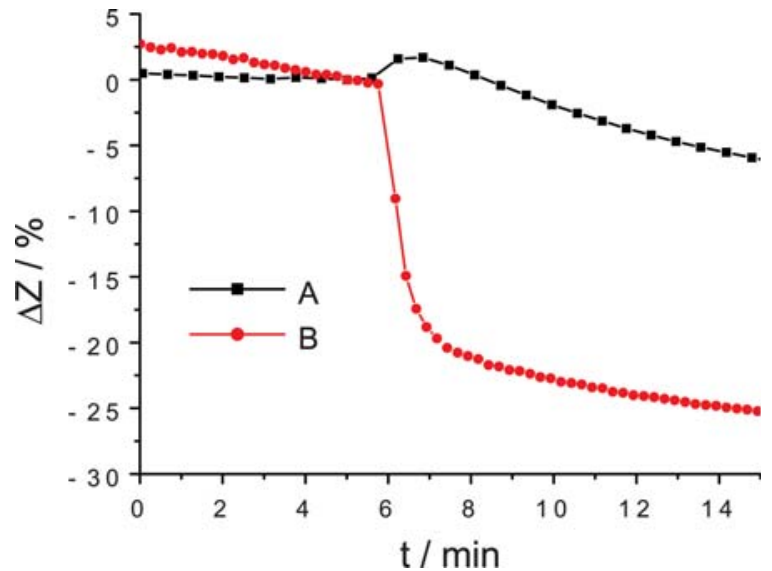

Fig. 3 Impedance change measured before and after addition of $10 \mathrm{U} \mathrm{ml}^{-1} \mathrm{HNE}$ to $\mathrm{pH} 7.5$ charge transfer buffer. Curve A shows the response of an AAPVAAK cross-linked hydrogel film produced by a single step coating method on a QCM crystal. Curve B shows the response of an AAPVAAK cross-linked hydrogel film produced by a two step coating method on a QCM crystal. HNE was added at $t=5 \mathrm{~min}$.

For the production of the final clinical device, the hydrogel films will be deposited using standard technologies such as drop coating or inkjet printing. As pre-mixing of the amine containing peptide and the oxidised dextran in solution prior to coating would lead to cross-linking, albeit at a slow rate, we did not anticipate being able to use this approach with any standard printing method. Hence a two-step coating method was developed in which the dextran and the peptide were deposited in two consecutive steps. Using this two step coating strategy, the cross-linking condensation reaction would only happen on the surface of the substrate instead of in nozzles or ink cartridges. Adopting this approach had the attendant advantage of producing a highly cross-linked surface layer on the dextran which provided a sufficiently rapid response to the enzyme. Presumably once the cross-links thus formed in the surface layer were broken by HNE, the underlying non-cross-linked dextran dissolved rapidly resulting in a large sensor response (Fig. 3, curve B).

\section{The effect of non-specific binding}

Further development work was carried out using hydrogel-coated IDEs on insulator/silicon and alumina substrates. $\mathrm{Cr} / \mathrm{Au}$ IDEs were obtained by microfabrication. It is anticipated that the microfabricated electrodes will be replaced by screen printed electrodes on alumina in the future to provide low-cost massproduced electrodes. Response curves to different activities of HNE using IDEs on a silicon substrate are shown in Fig. 4a. The impedance response is comparable to that observed with two opposing electrodes (Fig. 3, curve B). The rate of degradation was found to be strongly activity dependent.

Samples of GCF are expected to contain protein concentrations between $2 \%$ and $4 \%$. The effect of BSA on the rate of degradation was therefore investigated. Fig. 4 shows the comparison of the impedance change before and after the addition of three different activities of HNE in the absence and in the presence of $2 \%$ BSA. In the absence of BSA (Fig. 4a), the impedance change after the addition of $10 \mathrm{U}$ $\mathrm{ml}^{-1}$ was about $18 \%$ in $3 \mathrm{~min}$. The addition of BSA resulted in slower degradation (Fig. 4b). The impedance change in 3 min was $13 \%$ in the presence of $2 \%$ BSA. The reduction in the degradation rate was mainly attributed to an increase in the viscosity of the solution. The response in the presence of BSA remained sufficient 

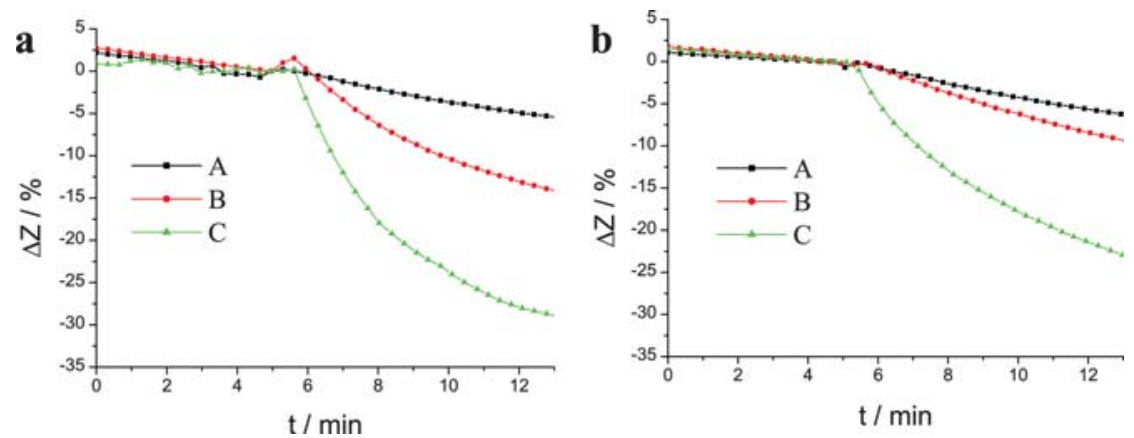

Fig. 4 Impedance change measured with AAPVAAK cross-linked hydrogel coated IDEs on silicon before and after addition of different concentrations of $\mathrm{HNE}\left(0.1 \mathrm{U} \mathrm{ml}^{-1}\right.$ (A), $1 \mathrm{U}$ $\mathrm{mL}^{-1}$ (B) and $10 \mathrm{U} \mathrm{ml}^{-1}$ (C)) to a $\mathrm{pH} 7.5$ charge transfer buffer containing (a) $0 \%$ BSA, (b) $2 \%$ BSA. HNE was added at $t=5 \mathrm{~min}$.

over the entire concentration range of HNE for obtaining adequate sensor signals in the 3 min timeframe required by the dental application.

\section{The effect of the monolayer on the mechanism of degradation}

If not specified, the gold electrodes on all substrates were modified with a hydroxyl terminated monolayer prior to hydrogel deposition to aid the spreading of the solution on the surface. To study the effect of the self-assembled monolayer on the degradation of hydrogel films, the gold IDEs were modified using two different thiols - one with a hydroxyl terminal group, which provided a hydrophilic surface but did not react with the oxidised dextran, and a second one with an amine terminal group that provided a hydrophilic surface, which was also capable of reacting with the aldehyde groups of the oxidised dextran. The response curves to both types of hydrogel films are shown in Fig. 5. Both films appeared stable in pH 7.5 charge transfer buffer. Upon addition of HNE, the hydrogel film on a hydroxyl terminated monolayer displayed a decrease in impedance caused by a dissolution of the film, while the hydrogel film formed on the amine terminated monolayer showed an increase in impedance indicative of a swelling rather than a dissolution process as

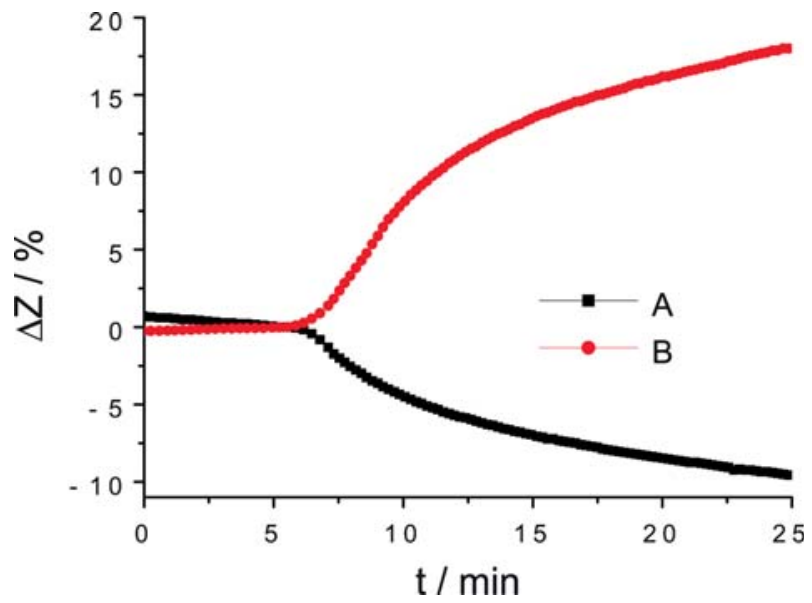

Fig. 5 Impedance change measured with an AAPVAAK cross-linked hydrogel coated on IDEs on $96 \%$ alumina modified with 4-mercapto-1-butanol as monolayer (A) and 2-aminoethanethiol as monolayer (B) before and after addition of $10 \mathrm{U} \mathrm{ml}^{-1} \mathrm{HNE}$ to $\mathrm{pH} 7.5$ charge transfer buffer. HNE was added at $t=6$ min. 
the dextran film was covalently bound to the surface after the cleavage of cross-links due to the enzymatic reaction.

The use of an amine terminated monolayer may be preferable in applications where greater mechanical stability is required, e.g. if the sensor were required to be placed into a flowing medium, and where the release of degradation products of the films is undesirable, e.g. for in vivo applications.

\section{Sensor response to different proteases}

Three host proteases, HNE, cathepsin G and MMP8, have been identified as suitable markers for monitoring periodontal disease (vide supra). Oxidised dextran films were thus cross-linked with three different peptides that each contained cleavage sites for one of the three target enzymes. The activity dependent response of the sensor materials to the different proteases was investigated. The response of AAPVAAK crosslinked films to different activities of HNE was discussed above (Fig. 4). Fig. 6a and 7a show the impedance change during degradation of dextran hydrogel films crosslinked with AAPFFK and GPQGIWGQK under the same experimental conditions. The film impedance for AAPFFK and GPQGIWGQK cross-linked films increased over time in the charge transfer buffer. This can be attributed to continued swelling of the films. Addition of the proteases caused the films to degrade for all three hydrogel/enzyme systems. At high enzyme activities, this resulted in a decrease of impedance; at low activities, this resulted in a reduced rate of impedance increase. Calibration curves for cathepsin G (Fig. 6b) and MMP8 (Fig. 7b) were obtained by determining the rate of degradation within the first $100 \mathrm{~s}$ of enzyme addition.

\section{Measurement of protease activities in small volumes}

A critical requirement of clinical measurements of GCF is the size of the sample volumes of $1-5 \mu$ l. To enable measurements in such small sample volumes, capillary fill devices were constructed on top of the hydrogel coated IDEs on alumina substrates. In contrast to the results shown above, there was no stabilisation period in PBS prior to the addition of enzyme solution, but the test solutions were added to the device directly. Sample response curves for different HNE activities are shown in Fig. 8. The response to $\mathrm{pH} 7.5$ charge transfer buffer shows a small decrease in impedance followed by a slow increase in the impedance with time. It is assumed that the decrease in impedance was caused by the hydration of the hydrogel film. The continued swelling of the film resulted in an increase of its thickness and therefore an increase in the impedance. The addition of HNE to the capillary fill device
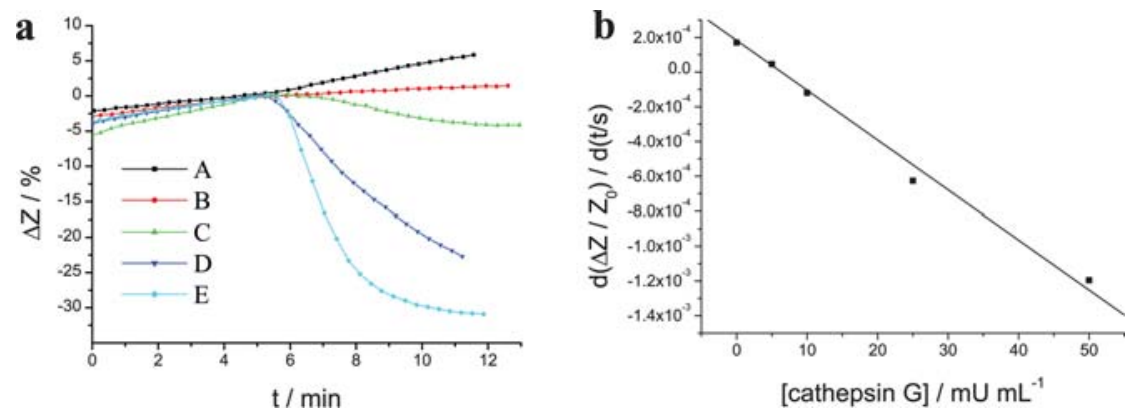

Fig. 6 (a) Impedance change measured with AAPFFK cross-linked hydrogel coated IDEs on alumina before and after addition of different activities of cathepsin $\mathrm{G}$ to $\mathrm{pH} 7.5$ charge transfer buffer: $0 \mathrm{mU} \mathrm{ml}^{-1}$ (A), $5 \mathrm{mU} \mathrm{ml}^{-1}$ (B), $10 \mathrm{mU} \mathrm{ml}^{-1}$ (C), $25 \mathrm{mU} \mathrm{ml}^{-1}$ (D), $50 \mathrm{mU} \mathrm{ml}^{-1}$ (E); (b) calibration curve showing the rates of impedance change for the first $100 \mathrm{~s}$ after the addition of cathepsin $G$ versus cathepsin $G$ activity. Points represent the average of two individual measurements at each activity. 

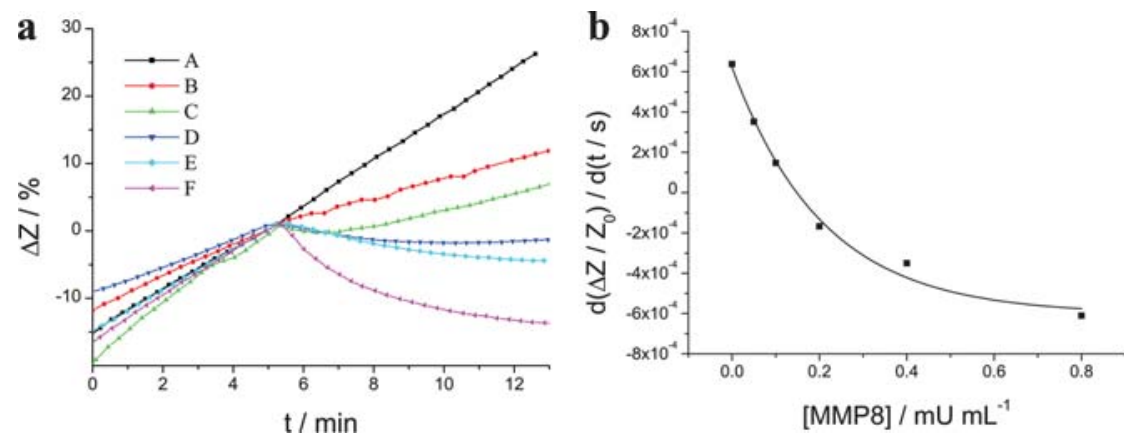

Fig. 7 (a) Impedance change measured with GPQGIWGQK cross-linked hydrogel coated IDEs on alumina before and after addition of different activities of MMP8 to a $\mathrm{pH} 7.5$ charge transfer buffer: $0 \mathrm{mU} \mathrm{mL}^{-1}(\mathrm{~A}), 0.05 \mathrm{mU} \mathrm{ml}^{-1}$ (B), $0.1 \mathrm{mU} \mathrm{ml}^{-1}$ (C), $0.2 \mathrm{mU} \mathrm{ml}^{-1}$ (D), $0.4 \mathrm{mU}$ $\mathrm{ml}^{-1}(\mathrm{E}), 0.8 \mathrm{mU} \mathrm{ml}^{-1}(\mathrm{~F})$; (b) calibration curve showing the rates of impedance change for the first $100 \mathrm{~s}$ after the addition of MMP8 versus MMP8 activity. Points represent the average of two individual measurements at each activity.

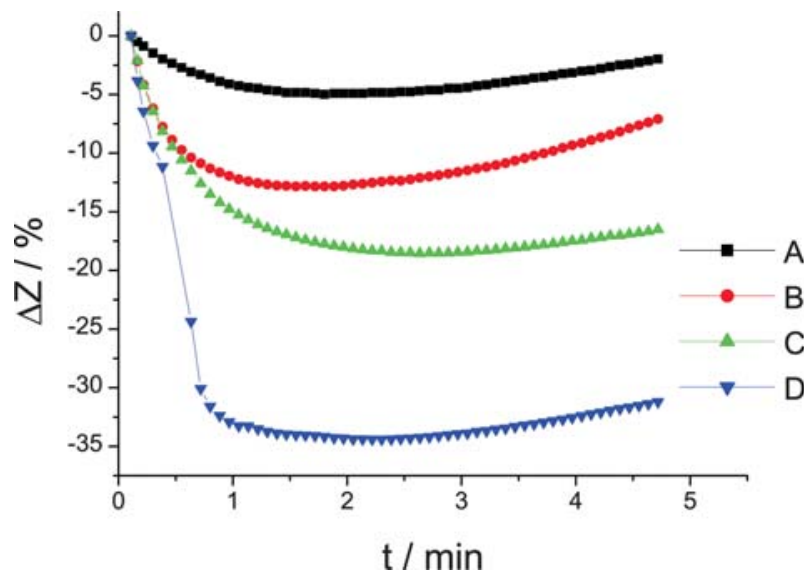

Fig. 8 Impedance change after filling capillary fill device on IDEs coated with an AAPVAAK cross-linked dextran hydrogel with $\mathrm{pH} 7.5$ charge transfer buffer containing different activities of HNE: $0 \mathrm{U} \mathrm{ml}^{-1}$ (A), $5 \mathrm{U} \mathrm{ml}^{-1}$ (B), $10 \mathrm{U} \mathrm{ml}^{-1}$ (C) and $30 \mathrm{U} \mathrm{ml}^{-1}$ (D).

caused a significant decrease of the impedance, the rate and extent of which were strongly dependent on the HNE activity. The response is deemed sufficiently large for the detection of HNE in clinical samples, i.e. the capillary fill device will form the basis for a prototype of the clinical device.

\section{Conclusions}

It has been shown that thin films of peptide cross-linked dextran hydrogel can be used to detect protease activities by monitoring the degradation of the films in the presence of the target protease and a charge transfer reagent using impedance measurements. The sensor materials are generic - specificity for a particular protease can be achieved by employing an appropriate peptide sequence as a cross-linker. To date, three markers for periodontal disease, HNE, cathepsin G and MMP8, have been detected using this sensor system. Preliminary results have shown that measurements in small sample volumes can be facilitated by using a sealed capillary fill device providing the basis for a prototype device for clinical applications. 
Depending on the self-assembled monolayer used to modify the electrode surface, hydrogel films were either shown to dissolve or to swell upon interaction with the target protease causing either a decrease or an increase in the impedance. Dissolution was achieved using a chemically inert monolayer with hydroxyl terminal groups, while swelling was observed when using an amine terminated monolayer, which bound the oxidised dextran covalently to the sensor surface. As a fairly high-molecular weight dextran was utilised, it can be assumed that most of the dextran molecules present in the film were bound to the surface in this manner. A surface-bound film may have advantages for applications where greater mechanical stability is required.

Measurements of the sensor response in the presence of BSA showed that background protein slowed down the sensor response. This was attributed to an increase in the viscosity of the solution and possibly to an interaction between the target protease and the dissolved protein.

\section{Acknowledgements}

The authors are grateful to the Technology Strategy Board (TP/8/BIO/6/I/Q0020H) for funding this project.

\section{References}

1 T. Sorsa, Y. L. Ding, T. Ingman, T. Salo, U. Westerlund, M. Haapasalo, H. Tschesche and Y. T. Konttinen, J. Clin. Periodontol., 1995, 22, 709-717.

2 J. M. Herrmann, J. R. Gonzales, R. H. Boedeker, J. Vonholdt and J. Meyle, J. Clin. Periodontol., 2001, 28, 31-37.

3 J. M. Mailhot, J. Potempa, S. H. Stein, J. Travis, J. D. Sterrett, P. J. Hanes and

C. M. Russell, J. Clin. Periodontol., 1998, 25, 578-584.

4 B. M. Eley and S. W. Cox, Br. Dent. J., 1998, 184, 323-328.

5 H. Y. Chen, S. W. Cox, B. M. Eley, P. Mantyla, H. Ronka and T. Sorsa, J. Clin. Periodontol., 2000, 27, 366-369.

6 T. J. Venaille, G. Ryan and B. W. S. Robinson, Respir. Med., 1998, 92, 233-240.

7 A. Gervaix, R. Thompson, J. G. Bieth, H. P. Nick and S. Suter, Eur. Respir. J., 1992, 5, $566-575$.

8 T. Tervahartiala, Y. T. Konttinen, T. Ingman, R. HayrinenImmonen, Y. Ding and T. Sorsa, J. Clin. Periodontol., 1996, 23, 68-75.

9 M. Wikstrom, J. Potempa, A. Polanowski, J. Travis and S. Renvert, J. Periodontol., 1994, 65, 47-55.

10 R. B. Millington, A. G. Mayes, J. Blyth and C. R. Lowe, Sens. Actuators, B, 1996, 33, $55-59$.

11 A. G. E. Saum, R. H. Cumming and F. J. Rowell, Biosens. Bioelectron., 2000, 15, 305-313.

12 N. M. Hanumegowda, I. M. White, H. Oveys and X. D. Fan, Sens. Lett., 2005, 3, 315-319.

13 R. E. Ionescu, S. Cosnier and R. S. Marks, Anal. Chem., 2006, 78, 6327-6331.

14 J. L. Stair, M. Watkinson and S. Krause, Biosens. Bioelectron., 2009, 24, 2113-2118.

15 X. D. Lou, L. Y. Zhang, J. G. Qin and Z. Li, Langmuir, 2010, 26, 1566-1569.

16 C. Sumner, A. Sabot, K. Turner and S. Krause, Anal. Chem., 2000, 72, 5225-5232.

17 C. Sumner, S. Krause, A. Sabot, K. Turner and C. J. McNeil, Biosens. Bioelectron., 2001, 16, 709-714.

18 S. Krause, C. J. McNeil, C. Fernández-Sánchez and A. Sabot, in Encyclopedia of sensors, ed. C. Grimes, American Scientific Publishers, 2006, pp. 289-306.

19 A. G. E. Saum, R. H. Cumming and F. J. Rowell, Biosens. Bioelectron., 1998, 13, 511-518.

20 M. M. Orosco, C. Pacholski, G. M. Miskelly and M. J. Sailor, Adv. Mater., 2006, 18, 1393.

21 A. Sabot and S. Krause, Anal. Chem., 2002, 74, 3304-3311.

22 Y. Zhou, S. Jiang, S. Krause and J. N. Chazalviel, Anal. Chem., 2007, 79, 8974-8978.

23 L. Ruys, J. Vermeersch, E. Schacht, E. Goethals, P. Gyselinck, P. Braeckman and R. Van Severen, Acta Pharm. Technol., 1983, 29, 105-112.

24 S. Netzelarnett, G. Fields, H. Birkedalhansen and H. E. Vanwart, J. Biol. Chem., 1991, 266, 6747-6755. 